\title{
Invasive infections due to Streptococcus pyogenes: seasonal variation of severity and clinical characteristics, Iceland, 1975 to 2012
}

L B Olafsdottir ${ }^{1}$, H Erlendsdóttir ${ }^{2,3}$, J Melo-Cristino4, D M Weinberger ${ }^{5,6}$, M Ramirez $^{4}$, K G Kristinsson ${ }^{2,3}$, M Gottfredsson $^{1,3}$

1. Department of Medicine, Landspitali University Hospital, Reykjavik, Iceland

2. Clinical Microbiology, Landspitali University Hospital, Reykjavik, Iceland

3. Faculty of Medicine, School of Health Sciences, University of Iceland, Reykjavik, Iceland

4. Institute of Microbiology, Institute of Molecular Medicine, Faculty of Medicine, University of Lisbon, Lisbon, Portugal

5. Division of International Epidemiology and Population Studies, Fogarty International Center, National Institutes of Health, Bethesda, Maryland, United States

6. Department of Epidemiology of Microbial Diseases, Yale School of Public Health, New Haven, Connecticut, United States

Citation style for this article:

Olafsdottir LB, Erlendsdóttir H, Melo-Cristino J, Weinberger DM, Ramirez M, Kristinsson KG, Gottfredsson M. Invasive infections due to Streptococcus pyogenes: seasonal variation of severity and clinical characteristics, Iceland, 1975 to 2012. Euro Surveill. 2014;19(17):pii=20784. Available online: http://www.

eurosurveillance.org/ViewArticle.aspx?Articleld=20784

Epidemiology and clinical characteristics of invasive Group A streptococcal infections (IGASI) are highly variable. Long-term studies are needed to understand the interplay between epidemiology and virulence. In a population-based study of IGASI in Iceland from 1975 to 2012,288 cases were identified by positive cultures from normally sterile body sites. Charts were reviewed retrospectively and emm-types of viable Streptococcus pyogenes isolates $(n=226)$ determined. Comparing the first and last decade of the study period, IGASI incidence increased from 1.09 to 3.96 cases per 100,000 inhabitants per year. The most common were emm types 1 (25\%), $28(11 \%)$ and $89(11 \%)$; emm 1 strains were most likely to cause severe infections. Infections in adults were significantly more likely to be severe during the seasonal peak from January to April (risk ratio: $2.36,95 \%$ confidence interval: 1.34-4.15). Significant seasonal variability in severity was noted among patients with diagnosis of sepsis, respiratory infection and cellulitis, with $38 \%$ of severe infections in January to April compared with $16 \%$ in other months ( $p<0.01)$. A seasonal increase in severity of IGASI suggested that generalised seasonal increase in host susceptibility, rather than introduction of more virulent strains may play a role in the pathogenesis of these potentially fatal infections.

\section{Introduction}

Streptococcus pyogenes, or Lancefield group A Streptococcus (GAS), is known for its ability to cause diverse clinical manifestations, including soft tissue infections, pneumonia, and toxic shock syndrome. Over the past 30 years there has been a concern about increasing incidence and severity of invasive group $A$ streptococcal infections (IGASI) [1-3], defined as infections associated with the isolation of the bacteria from a normally sterile body site. GAS has many virulence factors; a key factor is the $M$ protein of the cell wall for which more than 100 different types are known [4]. Sequencing of the $\mathrm{emm}$ gene and classification of the $M$ protein is often used to characterise GAS isolates [5] with studies from the United States (US) and Europe showing that isolates with $M$ types $1,3,4,6$ and 28 cause about $50 \%$ of IGASI [6-8].

IGASI are often life-threatening; The most severe clinical presentations are necrotising fasciitis (NF), an aggressive and rapidly destructive infection of deep subcutaneous tissue and fascia, characterised by necrosis of skin and underlying structures, and streptococcal toxic shock syndrome (STSS), defined as streptococcal infection associated with sudden shock and organ failure [3,9]. Certain risk factors for invasive infections have been established such as the extremes of age, immunosuppression, diabetes mellitus and loss of skin integrity $[10,11]$. The factors driving the increased incidence of IGASI are not completely understood, however, clinical and microbiological studies demonstrate a complex epidemiology with great spatiotemporal variation of this common pathogen.

It is well established that the incidence of GAS infections can fluctuate in time, both seasonally and over the course of several years. However, most published studies on IGASI are limited by a relatively short observation period. Studies have shown, with remarkable congruence between countries, an interesting seasonal pattern of non-invasive and invasive infections, with the incidence being high in the months January to March but low in late summer and autumn $[12,13]$. A large European study showed that several emm types had a uniform seasonal prevalence whereas other types exhibited more fluctuations [14]. Little is known about whether severity of infection varies seasonally. 
The purpose of this study was two-fold: Firstly, to provide a long term nationwide analysis of IGASI in Iceland by using clinical and population-based data to assess epidemiology, clinical characteristics, therapy and outcome. Secondly, to study seasonal variations in the incidence, severity, and clinical presentation of IGASI and the relationship to emm type prevalence.

\section{Methods}

\section{Setting and case definition}

We conducted a nationwide study of IGASI diagnosed in Iceland from 1 January 1975 to 31 March 2012. A case of IGASI was defined as isolation of GAS from a normally sterile body site, or isolation of the organism from a non-sterile site, in conjunction with the diagnosis of STSS or NF. Cases were identified through microbiology databases and hospital discharge diagnosis using the appropriate ICD codes (ICD-9 number (period 1983-96): 728.0; ICD-10 numbers (period 1997-2005): A48.3; M60.0; M63.0; M63.2). Using these criteria, 288 cases were identified and for these, 275 records were retrieved and reviewed retrospectively (yield: $96 \%$ ), but age and vital status was known for all 288 cases. Cases were defined as severe, if their condition required admission to intensive care and/or if the patient died from the infection during hospitalisation. The study was approved by the Icelandic National Bioethics Committee, by the Data Protection Authority of Iceland, and by the responsible Chief Medical Officer at healthcare facilities where clinical data were obtained.

\section{Data collection}

Data collected included age, sex, past medical history, medication, presenting symptoms, physical findings, and laboratory results upon admission and treatment. The main antibiotic treatment was defined as the antibiotic used for at least half of the treatment duration.

\section{Microbiology and emm typing}

During the first 15 years of the study, a Bactec (Becton Dickinson Microbiology Systems) radiometric system was most widely used. During 1990-2001, Bactec (Becton Dickinson), ESP (Difco) and bioMérieux Vital (bioMérieux) nonradiometric systems were used. The BacT/Alert system (bioMérieux) was used from 2002 $[15,16]$. Invasive specimens, except blood cultures, were inoculated on blood agar and chocolate agar plates (Difco) and incubated under a humidified atmosphere containing $5 \% \mathrm{CO}_{2}$, as well as anaerobically for $24 \mathrm{hr}$. All positive blood culture bottles showing Grampositive streptococci were inoculated in the same manner. All isolates were kept in Trypticase Soy Broth (TSB; Becton Dickinson) containing $20 \%$ glycerol and stored at $-80^{\circ} \mathrm{C}$. The emm-typing of isolates was performed according to the protocols and recommendations of the US Centers for Disease Control and Prevention (CDC) [17], and the first 240 bases of each sequence were searched against the emm CDC database [4]. Identity of at least $95 \%$ with previously described sequences over the first 150 bases considered allowed the assignment of an emm type. Sequencing was done by the Sanger method using an Applied Biosystems 3730xl DNA Analyzer. Subtyping was not performed.

\section{Statistical analysis}

The national population registry was used to calculate incidence and age-specific incidence rates (population data available at Statistic Iceland [18]). The crude inhouse and 30-day mortality was assessed using hospital records and the national population registry.

Comparison of categorical variables was performed using Fisher's exact test and Pearson's test using SPSS, version 10.5. Level of significance was set at p<0.05, and all tests were two-tailed. Risk ratios or incidence rate ratios and their associated $95 \%$ confidence intervals $(\mathrm{Cl})$ were calculated using log-linked models (Poisson or binomial distribution, as appropriate) in PROC GENMOD (SAS v9.2). Dummy variables were used to test the risk or incidence during a given time period with the noted reference time period. We also considered whether influenza activity was associated with increased GAS incidence. To do this, we fit a Poisson regression where the outcome was monthly GAS cases, and included predictors for linear trend, monthly indicator variables for the winter months and influenza epidemic periods [19]. Influenza epidemic periods were defined as month when influenza activity was significantly above a harmonic seasonal baseline, determined using Serfling regression [20]. We included data between 1985 and 2008 for the influenza analyses.

\section{Results}

\section{Epidemiology}

From 1 January 1975 to 31 March 2012, 288 cases of IGASI were identified, including 54 children ( $\leq 16$ yearsold) and 234 adults. There were slightly more female (54\%) than male cases. The number of cases diagnosed by six-year intervals is shown in Figure $1 \mathrm{~A}$. The incidence during 1975 to 1986 was 1.09 cases per 100,000 inhabitants per year and rose to 3.08 and 3.96 cases per 100.000 inhabitants per year during 1987 to 1998 and 1999 to 2010 , respectively (rate ratios: $2.82 ; 95 \%$ $\mathrm{Cl}: 1.87-4.25$ and 3.63; $95 \% \mathrm{Cl}: 2.45-5.38)$. Figure $1 \mathrm{~B}$ shows the age-specific incidence rates for both halves of the study, 1975 to 1993 and 1994 to 2012, highlighting an increase in most age groups during the second half, which is not explained by difference in age composition between study periods. The age-specific incidence was highest at both extremes of age (Figure $1 \mathrm{~B}$ ).

\section{Clinical characteristics}

In this retrospective study 162 of the 231 evaluable cases, had at least one underlying medical condition recorded, including cardiovascular disease in 59, malignancy in 34 , respiratory disease in 28 , diabetes mellitus in 12 and alcohol and/or substance abuse in 14 of the 231 . In five cases, the infection was linked 


\section{FIGURE 1}

Epidemiology of invasive Group A streptococcal infection in Iceland

A. Number of diagnosed cases by six-year intervals, 1975-2010 $(n=267)$

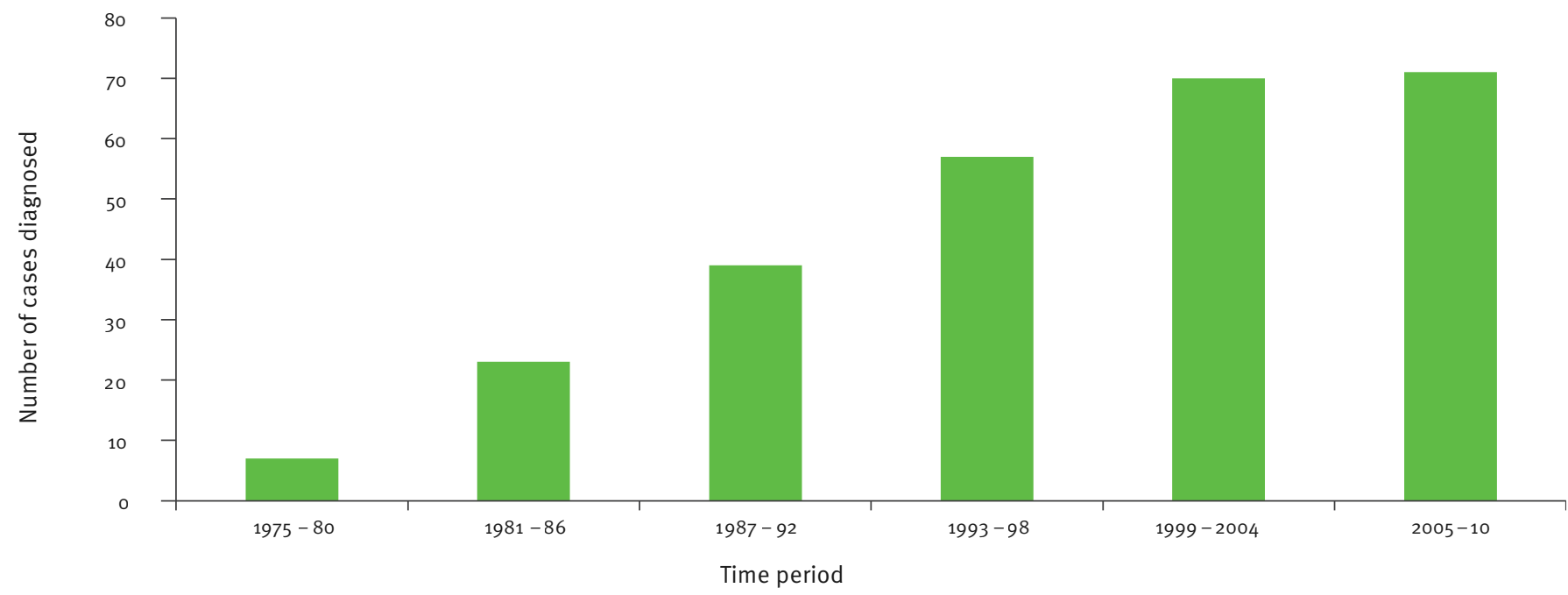

The incidence during 1975-86 was 1.09 cases/100,000 inhabitants/year and rose to 3.96 cases/100,000 inhabitants/year during $1999-2010$.

B. Age-specific incidence, $1975-2012(n=288)$

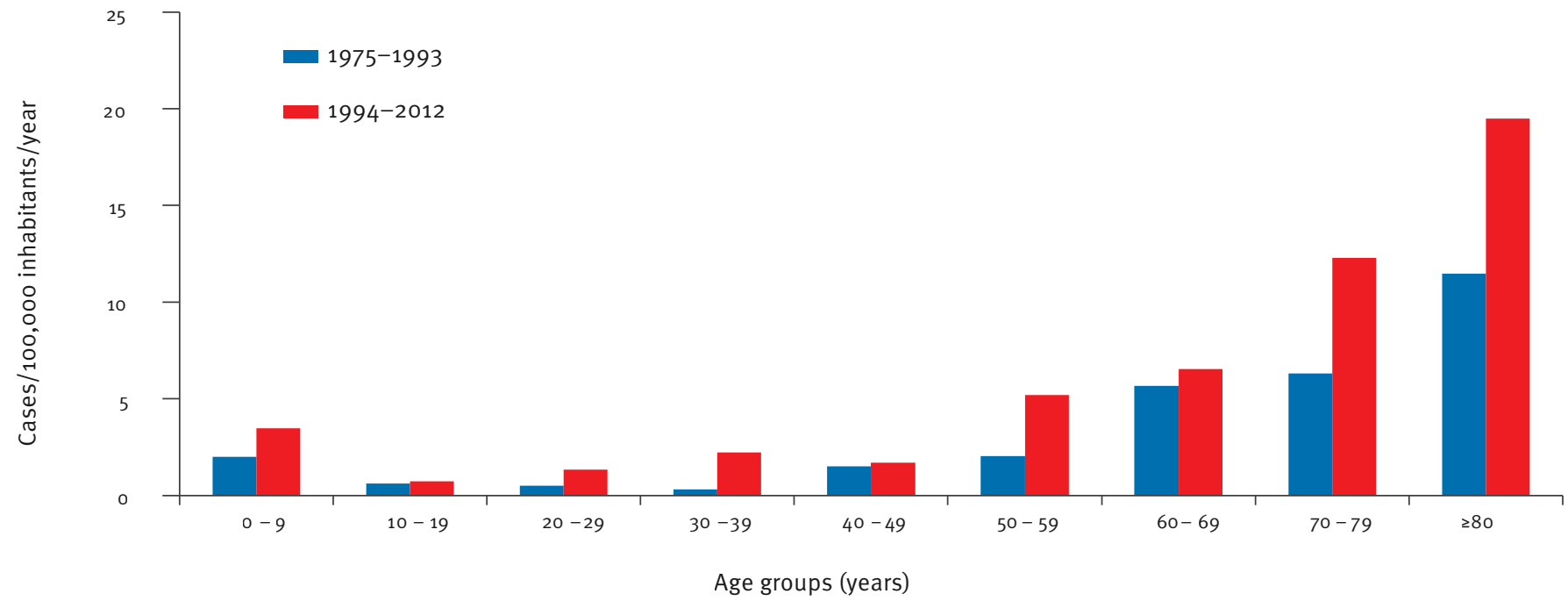

Blue bars: incidence rates for the first half of the study; red bars: incidence rates for second half. The incidence almost doubled in almost all age groups.

to illicit intravenous drug use. No patient had underlying human immunodeficiency virus (HIV) infection in our cohort, whereas five children had chickenpox. Drug information prior to admission was available for 198 patients, of whom 19 were receiving immunosuppressive therapy and eight had received antibiotics before admission; there was documented non-steroidal antiinflammatory drug (NSAID) usage prior to admission in 25 patients.

The association between age, clinical characteristics and outcome (severe and non-severe) is shown in Table 1. Skin/soft tissue infections were the most common manifestation, diagnosed in $33 \%$ of the cases, followed by sepsis in $24 \%$. Puerperal sepsis was diagnosed in eight women and three children. STSS and NF were diagnosed in $11 \%$ of the cases, and there was an increase in the number of STSS and NF cases diagnosed during the study period, with only four cases documented from 1975 to 1994, compared with 10 cases from 1995 to 2004 and 18 cases from 2005 to 2012.

\section{Therapy and outcome}

The most common treatment was a beta-lactam antibiotic (208/219), usually penicillin. In severe infections 
TABLE 1

Age-specific incidence per 100,000 per year, clinical syndrome and severity ${ }^{\mathrm{a}}$ of invasive Group A streptococcal infections in Iceland, 1975-2012 ( $\mathrm{n}=288)$

\begin{tabular}{|c|c|c|c|c|c|c|c|c|c|}
\hline \multirow{2}{*}{ Syndrome } & \multicolumn{9}{|c|}{ Age (years) } \\
\hline & $0-9$ & $10-19$ & $20-29$ & $30-39$ & $40-49$ & $50-59$ & $60-69$ & $70-79$ & $\geq 80$ \\
\hline Arthritis & 0.26 & 0 & 0.06 & 0.14 & 0.16 & 0.30 & 0.55 & 0.60 & 0.75 \\
\hline $\begin{array}{l}\text { Skin/soft } \\
\text { tissue }\end{array}$ & 0.49 & 0.18 & 0.31 & 0.35 & 0.73 & 1.31 & 2.06 & 3.20 & 7.93 \\
\hline Other ${ }^{\mathrm{a}}$ & 0.43 & 0 & 0.06 & 0.07 & 0.16 & 0.40 & 1.10 & 2.40 & 2.24 \\
\hline $\begin{array}{l}\text { Respiratory } \\
\text { tract infection }\end{array}$ & 0.31 & 0.06 & 0 & 0.07 & 0 & 0.20 & $0.27 \%$ & 1.00 & 2.61 \\
\hline Sepsis & 1.22 & 0.12 & 0.31 & 0.42 & 0.40 & 0.71 & 1.37 & 2.20 & 2.20 \\
\hline STSS & 0.06 & 0 & 0.19 & 0.14 & 0.16 & 0.71 & 0.41 & 0.40 & 0 \\
\hline NF & 0 & 0 & 0 & 0.21 & 0 & 0.30 & 0.41 & 0 & 1.12 \\
\hline
\end{tabular}

NF: necrotising fasciitis; STSS: streptococcal toxic shock syndrome.

a The category "Other" includes bacteraemia with unclear focus of infection (14 cases), osteomyelitis (five cases) and upper respiratory infection (seven cases). It also includes 18 cases for whom information other than culture data, age, sex and vital status was unknown.

\section{FIGURE 2}

Distribution of emm types during the study period, Iceland, 1975-2012 (n=226 cases)

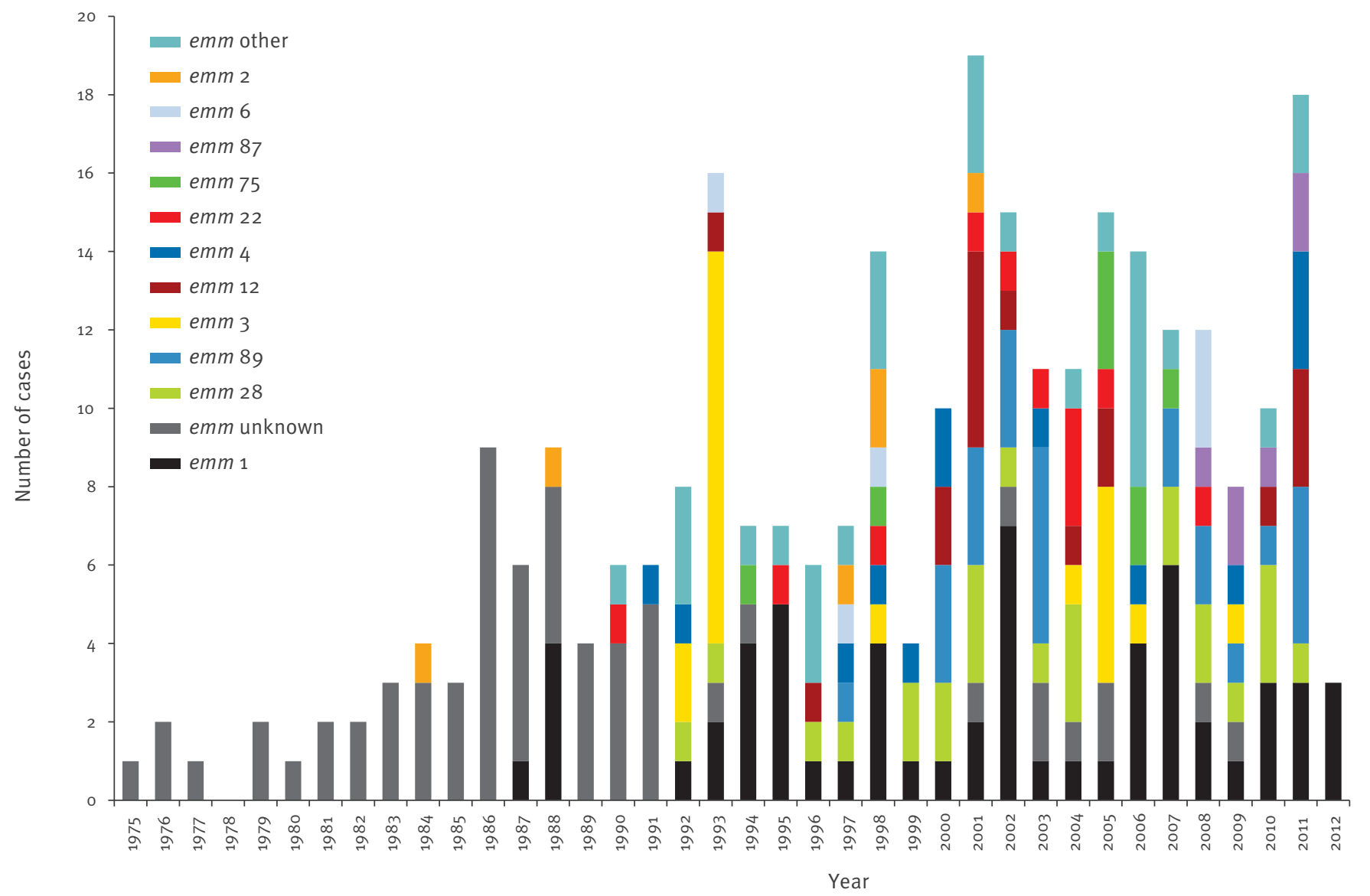

For 2012, the first three months are included.

The emm types showed much fluctation in prevalence during the study period. 
$(n=83)$, other drugs were used in combination, most commonly clindamycin (27/219), followed by aminoglycosides (27/219). The average length of parenteral antibiotic treatment was 11.9 days. During the study period, 77 of the 256 patient for whom we had this information were admitted to an intensive care unit (ICU), 56 of them needed inotropic drugs, 28 required mechanical ventilation and 10 received dialysis for renal failure.

The crude 30 -day mortality was $13.4 \%$ in adults and $5.6 \%$ in children. STSS or NF was associated with a significantly higher mortality rates than other infections in adults (29\% vs $11 \%$; risk ratio: $2.68 ; 95 \% \mathrm{Cl}$ : $1.36-5.27)$.

\section{emm types}

Overall 25 different emm types were identified among the 226 viable isolates that were recovered between 1987 and 2012. Figure 2 shows the emm types obtained during the study period. Table 2 shows the distribution of emm types in children compared with adults. The most common types were emm 1 ( $25 \%), 28$ (11\%), 89 (11\%), 3 ( $9 \%), 12(8 \%)$. Among the 25 cases (10 female, 15 male), no child was diagnosed with emm 28 , and only one case of puerperal sepsis was caused by emm 28 .

The association between clinical presentation, emm types, and severity is summarised in Table 3. Patients infected by emm 1-type strains, compared with all other emm types identified, were more likely to have severe disease ( $p<0.03)$, whereas patients with emm89 had a less severe course of disease, required intensive care less frequently and had no fatalities $(p=0.05)$. In addition, the severity differed greatly by clinical presentation, with NF (4 of 12 cases) and STSS (6 of 20 cases) being associated with a fatal outcome in $31 \%$ of cases. Invasive respiratory tract infection ( $4 / 23$ cases) and sepsis (12/69 cases) were associated with a fatal outcome in $17 \%$ of cases. All cases linked to illicit intravenous drug use were caused by different emm types. Puerperal sepsis was caused by emm type 1 in six cases and emm types 3, 4, 28, 77, 89 in one case each. Clinical syndromes of cellulitis and arthritis were associated with least mortality, three of 95 and o of 22 cases, respectively.

Seasonality of incidence and severity of invasive Group A streptococcal infection

There was significant seasonal variation in the incidence of IGASI (Figure 3). The association between incidence by month and clinical presentation is given in Figure 3A, demonstrating that the diagnoses of sepsis, NF and STSS were more common in mid- to late winter with nine of $12 \mathrm{NF}$ cases and eight of 20 STSS cases diagnosed during January to April. Figures $3 \mathrm{~B}$ and ${ }_{3} C$ show the incidence by severity and month of diagnosis in children and adults, respectively. The incidence peaked in late winter and early spring, specifically in January to February for children, and in April for adults. No seasonal variation in severity was noted
TABLE 2

Streptococcus pyogenes emm types identified during the study period, Iceland, $1975-2012$ ( $\mathrm{n}=226$ cases)

\begin{tabular}{|c|c|c|c|c|}
\hline emm type & children & adults & total & $p$ value \\
\hline 1 & 12 & 47 & 59 & 0.85 \\
\hline 2 & 1 & 5 & 6 & 1.00 \\
\hline 3 & 3 & 18 & 21 & 0.84 \\
\hline 4 & 6 & 7 & 13 & 0.04 \\
\hline 5 & 0 & 3 & 3 & 1.00 \\
\hline 6 & 3 & 3 & 6 & 0.16 \\
\hline 8 & 0 & 4 & 4 & 0.87 \\
\hline 9 & 0 & 1 & 1 & 1.00 \\
\hline 11 & 0 & 2 & 2 & 1.00 \\
\hline 12 & 6 & 11 & 17 & 0.15 \\
\hline 22 & 5 & 6 & 11 & 0.07 \\
\hline 28 & 0 & 25 & 25 & $<0.01$ \\
\hline 43 & 0 & 1 & 1 & 1.00 \\
\hline 58 & 0 & 1 & 1 & 1.00 \\
\hline 75 & 0 & 8 & 8 & 1.00 \\
\hline 77 & 0 & 3 & 3 & 1.00 \\
\hline 81 & 0 & 3 & 3 & 1.00 \\
\hline 84 & 0 & 1 & 1 & 1.00 \\
\hline 85 & 0 & 1 & 1 & 1.00 \\
\hline 87 & 1 & 5 & 6 & 1.00 \\
\hline 89 & 1 & 24 & 25 & 0.06 \\
\hline 94 & 1 & 4 & 5 & 1.00 \\
\hline 102 & 0 & 1 & 1 & 1.00 \\
\hline 110 & 0 & 2 & 2 & 1.00 \\
\hline 118 & 0 & 1 & 1 & 1.00 \\
\hline Unknown & 15 & 47 & 62 & 0.29 \\
\hline Total & 54 & 234 & 288 & \\
\hline
\end{tabular}

Overall, 226 (74\%) of invasive isolates (dating from 1987 to 2012) were available for emm sequencing. The most common emm types were 1, 28 and 89 which comprised nearly half of all the cases. As shown, emm type 4 was significantly more common among children $(p=0.04)$, whereas $\mathrm{emm} 28$ was seen solely among adults $(p=0.01)$.

among children, but the group was small with relatively few fatalities. Among adults, cases of IGASI were significantly more likely to be severe (resulting in death or ICU admission) during the seasonal peak in January to April than in the period June to September (Figure ${ }_{3} \mathrm{C}$ ) (risk ratio: $2.36,95 \% \mathrm{Cl}: 1.34-4.15$ ). No association was found between IGASI and influenza epidemic period. The number of cases occurring per season in this study may be insufficient to detect such an increase above the seasonal baseline.

It is possible that the seasonal variations in severity were simply a result of differing clinical presentations during the peak months, so we examined the individual seasonal variations in severity of those with a diagnosis of sepsis, respiratory infections, or cellulitis (excluding NF and STSS patients and arthritis or other clinical manifestations due to small numbers). There was significant seasonal variability in severity among these cases, with $38 \%$ of severe infections in January 
Clinical manifestations associated with invasive Group A streptococcal infection and emm types, Iceland, 1975-2012 (n=226 cases)

\begin{tabular}{|c|c|c|c|c|c|c|c|c|c|c|}
\hline Syndrome & emm 1 & emm 28 & emm 89 & emm 3 & emm 12 & $\begin{array}{c}\text { Other emm } \\
\text { types }\end{array}$ & $\begin{array}{l}\text { emm type } \\
\text { unknown }\end{array}$ & Total & Fatal & $\begin{array}{l}\text { ICU and/or } \\
\text { fatal }\end{array}$ \\
\hline Arthritis & 2 & 1 & 4 & 0 & 2 & 10 & 3 & $22(7.6 \%)$ & $\mathrm{O}(0 \%)$ & $3(13.6 \%)$ \\
\hline $\begin{array}{l}\text { Skin/soft } \\
\text { tissue }\end{array}$ & 5 & 9 & 10 & 6 & 8 & 27 & 30 & $95(33.0 \%)$ & $3(3.2 \%)$ & $7(7.4 \%)$ \\
\hline Other & 10 & 3 & 5 & 5 & 2 & 11 & 11 & $47(16.3 \%)$ & $5(10.6 \%)$ & $11(23.4 \%)$ \\
\hline $\begin{array}{l}\text { Respiratory } \\
\text { tract infection }\end{array}$ & 9 & 3 & 0 & 3 & 1 & 3 & 4 & $23(8.0 \%)$ & $4(17.4 \%)$ & $13(56.5 \%)$ \\
\hline Sepsis & 22 & 8 & 2 & 6 & 3 & 17 & 11 & $69(24.0 \%)$ & $12(17.4 \%)$ & $\begin{array}{c}24 \\
(34.8 \%)\end{array}$ \\
\hline STSS & 8 & 1 & 2 & 1 & 0 & 5 & 3 & $20(6.9 \%)$ & $6(30.0 \%)$ & $20(100 \%)$ \\
\hline NF & 3 & 0 & 2 & 0 & 1 & 6 & 0 & $12(4.2 \%)$ & $4(33.3 \%)$ & $11(91.7 \%)$ \\
\hline Total & 59 & 25 & 25 & 21 & 17 & 79 & 62 & 288 & 34 & 89 \\
\hline Fatal & $12(20.3 \%)$ & $4(16.0 \%)$ & $\mathrm{O}(0 \%)$ & $2(9.5 \%)$ & $2(11.8 \%)$ & $6(7.6 \%)$ & $8(12.9 \%)$ & & & \\
\hline $\begin{array}{l}\text { ICU and/or } \\
\text { fatal }\end{array}$ & $27(45.8 \%)$ & $8(32.0 \%)$ & $6(24.0 \%)$ & $7(33.3 \%)$ & $3(17.6 \%)$ & $21(26.6 \%)$ & $11(17.7 \%)$ & & & \\
\hline
\end{tabular}

ICU: intensive care unit; NF: necrotising fasciitis; STSS: streptococcal toxic shock syndrome.

The clinical presentation of emm 1, the most common emm type ( $25 \%$ of isolates), was in over $50 \%$ of cases sepsis, STSS and NF, while emm 28 ( $11 \%$ of isolates), 89 ( $11 \%$ of isolates) and 12 ( $8 \%$ of isolates) more often caused soft tissue infections.

to April compared with $16 \%$ of severe infections in other months $(p<0.01)$. There was also significant seasonal variation in the severity of arthritis and nonfocal infections: $32 \%$ were severe in January to April compared with $5 \%$ during the rest of the year ( $p<0.05$ ). There were too few cases of non-severe NF and STSS to evaluate seasonal variations. Analyses of adults infected with emm type 1 showed that $75 \%$ of cases were severe in January to April compared with $37.5 \%$ in June to September, but this difference was not statistically significant ( $p=0.09$, Fisher's exact test).

\section{Discussion}

We present a long-term population-based study of IGASI in Iceland, a setting where these infections are frequent compared with other Western developed nations. The study had a long observation period, and clinical as well as microbiological data were analysed.

The incidence of IGASI varies greatly by geographical location. Published studies from Europe show an incidence in northern European countries of 2.5 to 3.1 per 100.000 inhabitants per year in Finland, Denmark and Norway $[6,7]$, which is within the range of the estimates presented here. During the last decade, the incidence rate in our study was 3.96 per 100.000 inhabitants per year, i.e. even higher than corresponding figures from other Nordic countries $[6,7,13]$. The results are also in accordance with other reports, which show an increase starting in the 1980 s [21]. Currently, the global number of IGASI is estimated to be 663,000 new cases and 163,000 deaths each year, which is higher than that caused by measles $[21,22]$.
The reasons for the increased incidence are not yet entirely clear. In the first decade of the current study, more sensitive blood culture methods as well as improved access to these diagnostic tools may have played a role in improved detection. Such technical explanations are less plausible for the last 15 to 20 years of the study, when potential technical confounders have remained fairly unchanged. Another possible explanation is the periodic introduction of new, more virulent GAS strains, possibly carrying novel $M$ proteins on their surface, for which there may be low herd immunity.

Our results show a higher age-specific incidence in the age groups under 10 and over 60 years-old, which is in agreement with other studies [2,13], probably reflecting the relative lack of sufficient immune responses at the extremes of age. Similarly, the most common clinical presentation is soft tissue infection followed by sepsis or bacteraemia without identified focus, which is in agreement with other studies $[2,13,23]$. Interestingly, there was a trend of more severe infections in the latter half of the study; the number of cases with NF and STSS almost doubled between 1995 to 2004 and 2005 to 2012, although the second interval was shorter. Other investigators have shown that $58-67 \%$ of individuals with IGASI have at least one underlying disease [11]. Malignancies, cardiovascular diseases, diabetes and alcoholism are most frequently implicated, and this is borne out by the current study. Chickenpox is also strongly associated with invasive bacterial super-infection with GAS [10]; only five children had chickenpox in our cohort, precluding meaningful calculations of the relative risk for GAS infections following chickenpox. 


\section{FIGURE 3}

Seasonality, clinical manifestations and severity of invasive infections by Group A Streptococci in Iceland, 1975-2011 (n=285)

A. Clinical syndromes

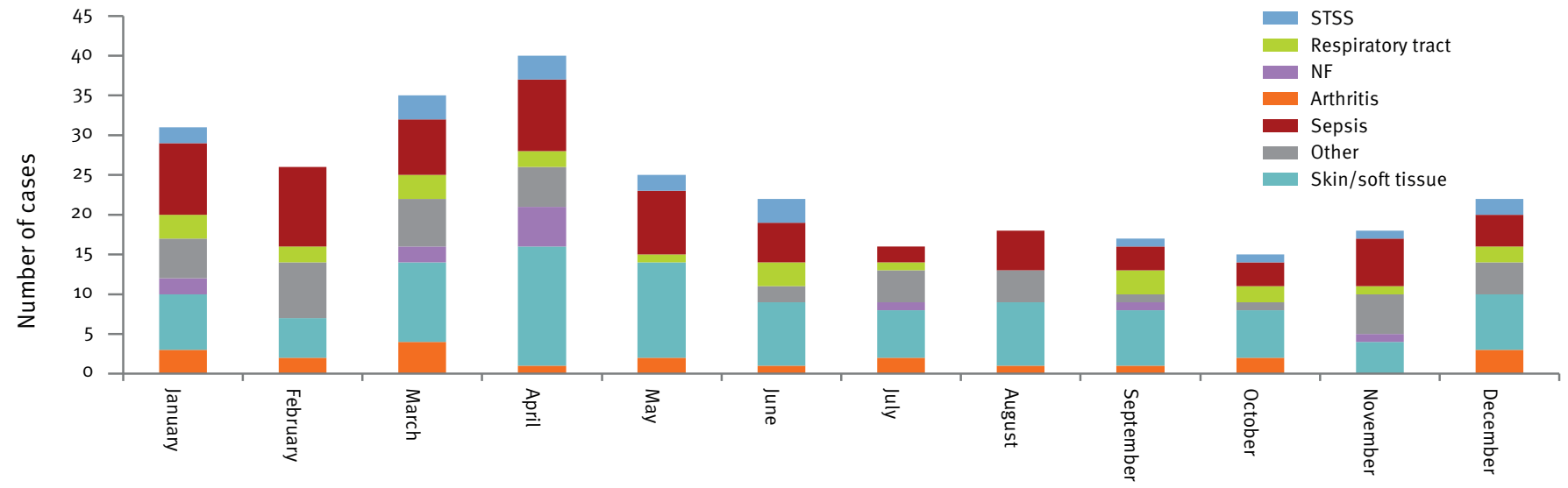

B. Severe and non-severe cases in children $(n=54)$

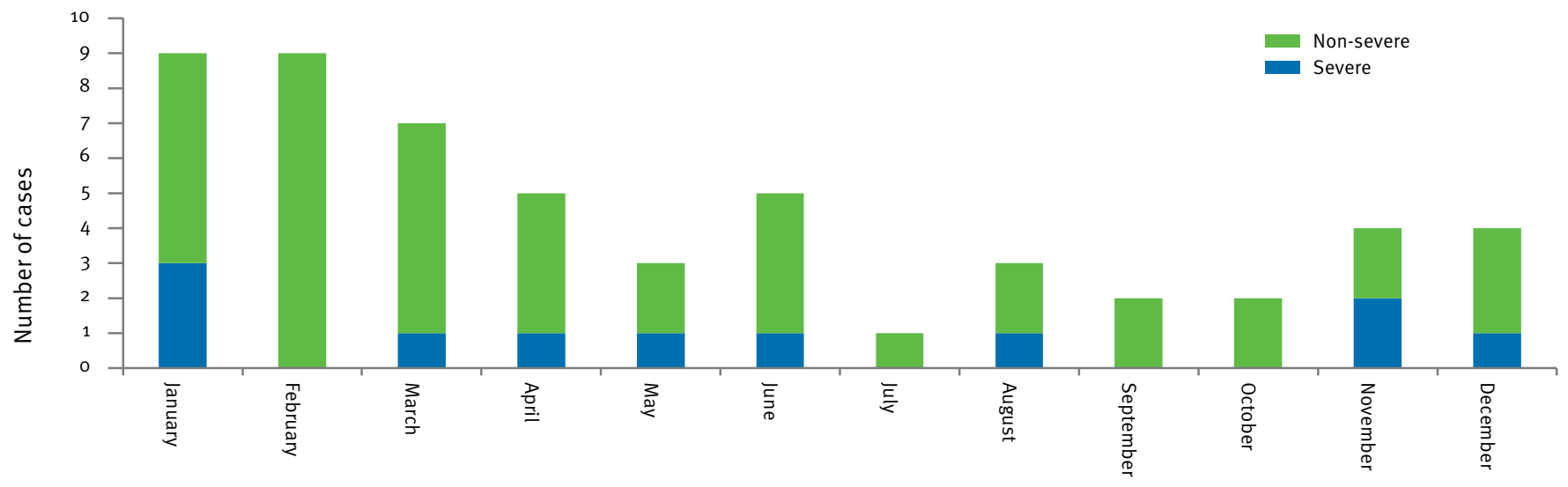

C. Severe and non-severe cases in adults $(n=231)$

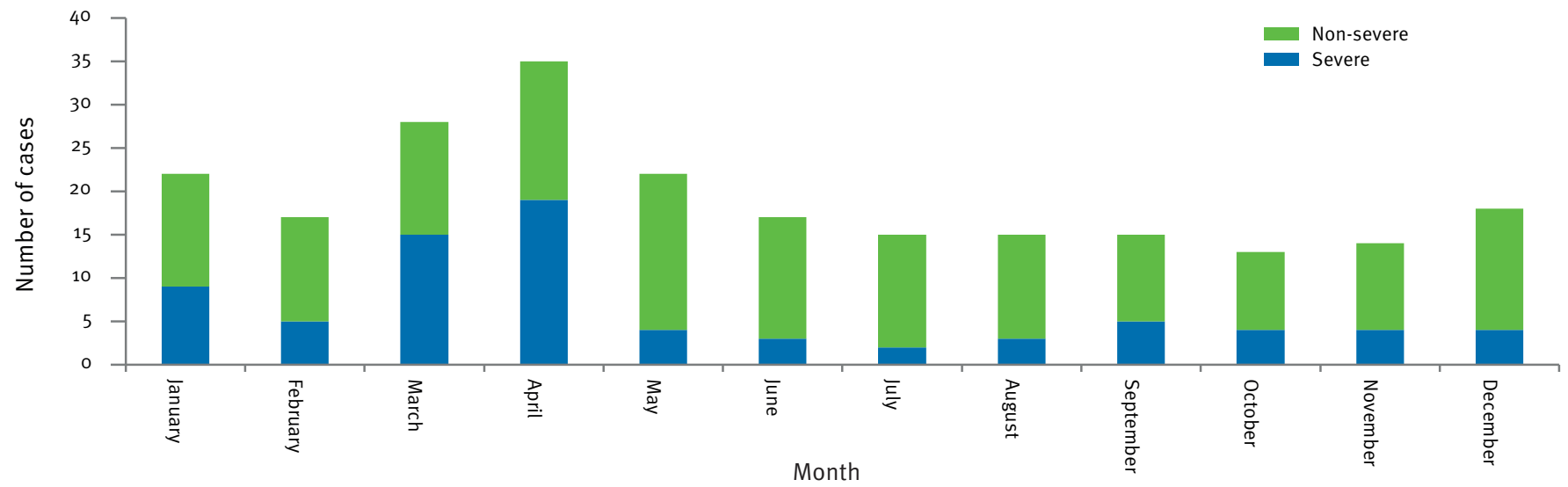

NF: necrotising fasciitis; STSS: streptococcal toxic shock syndrome.

A. The more aggressive cases (STSS, NF, sepsis) cluster in mid- to late winter.

B. The incidence reached a peak in January to February, but the severity was low in most cases, with no significant difference between winter and summer months (18\% severe in summer vs $17 \%$ in winter).

C. The incidence peaked in April, with significant seasonal increase in severity, as defined as admission to intensive care and/or death. 
The antibiotic treatment did not change during the study period. Penicillin is still the drug of choice in the treatment of streptococcal infections, with the addition of clindamycin in cases of STSS or NF and possibly intravenous immunoglobulin in select circumstances. No patient in this cohort received immunoglobulin.

In this study, the overall fatality was significantly higher among patients who developed STSS or NF. This is consistent with results from previous studies, including a study conducted in Sweden in 2002 to 2004 and a large European study in which 11 nations participated in the years 2003 and 2004 [11,13]. Almost half of all fatalities occurred within the first 48 hours of admission. These results are comparable to that of another study [24], emphasising the importance of early recognition and treatment.

A GAS clone carrying the $M_{1}$ (emm1) surface protein was first identified in the mid-1980s and associated with resurgence of serious streptococcal infections [25]. The M protein, encoded by emm, is a fimbrial protein located on the cell surface and an important virulence factor with anti-phagocytic properties. On the other hand, the risk of severe IGASI may also be determined in part by the genetic susceptibility of the host $[26,27]$. Over a 25-year period, 25 different emm types were identified in Iceland. This emm distribution found in the current study was similar to that found in other Nordic countries $[6,7]$. In our cohort, emm4 was significantly more common among children, whereas emm 28 was seen solely among adults. The reason for this discrepancy between children and adults is unclear but may be reflective of differences in specific immunity between age groups. In Europe, the most prevalent emm types in adults are, in descending order, emm1, emm28, emm3 and emm89; also in children, emm1 is the most common isolate, followed by emm12, emm4, emm3 and emm28 [14].

The study of associations between emm types and clinical manifestations is challenging due to the vast number of circulating emm types. Spread of otherwise uncommon emm types among disadvantaged populations has been well described $[28,29]$. There are indications that cellulitis may more often be caused by emm87, emm83 or emm81, whereas STSS and NF have been linked to emm1 and puerperal sepsis to emm28 $[11,14]$. Our study did suggest a significant association between infections caused by emm1 and severe disease, whereas patients with emm89 and 12 had less severe disease courses. The reasons why certain emm types are capable of causing more severe disease is unknown, but may be related to their associations with yet another virulence trait, such as production of SpeA, SpeZ and SpeJ exotoxins [30]. However, no correlation between clinical manifestations and a single superantigen gene in GAS has been found [11].
Seasonality of pharyngitis and invasive disease caused by GAS has been documented previously. Studies have shown, with remarkable congruence between countries, that the overall incidence of invasive infections varies by month $[2,13]$. We also observed significant seasonal variation, with the incidence among adults being highest in March and April. Underlying causes of seasonality are incompletely understood, but explanations such as preceding viral infections and seasonal changes in behavioural patterns, e.g. increased in-door activities during winter, have been proposed as potentially increasing the likelihood of transmission $[2,13]$. The similarity between countries may also be suggestive of an environmental factor occurring in several countries at the same time, such as decrease in sunlight and possibly simultaneous increased host susceptibility [31]. In support of this theory, we observed an association between severity of IGASI and seasonality, with a higher proportion of severe cases in January to April compared with the average in June to September. Another study from the United Kingdom [24] had also demonstrated a seasonal difference in case severity, with more severe infections diagnosed in January.

The seasonal variation that was noted here does correspond very closely to the traditional influenza season in Iceland [19]. In addition, concurrent infections with influenza and GAS have been reported, with an apparent increase in mortality when compared with influenza alone [32]. However, we tested for, but did not detect, an association between IGASI in Iceland and the influenza epidemic period. The number of cases occurring per season in this study may be insufficient to detect such an increase above the seasonal baseline. This is in contrast to a previous Canadian study which showed an association with Influenza B, which accounted for about $8 \%$ of the incidence of IGASI over any effect associated with modelled seasonal and long-term trends [33].

Seasonal variation in vitamin $D$ levels has been proposed to affect immune function [34]. Indeed, previous work from Iceland has shown that vitamin D levels are lowest in February to March and highest in June to July [35]. Thus, it would be interesting to investigate further the impact vitamin D level has on severity of GAS infections. An alternate hypothesis of introduction of more virulent strains during the winter months was not borne out by our data, seeing as cases with emm1 type were more severe in winter than in summer. Likewise, the proportion of emm1 types among all adult disease isolates was comparable in winter (22\%) and summer (15\%).

In summary, GAS remains a major public health concern, with this pathogen showing great variability over time in incidence and clinical presentation. In this longterm, nationwide study, we show a seasonal increase in disease severity in patients with sepsis, respiratory infections or cellulitis caused by GAS during January 
to April compared with other months. This pattern was also evident in patients with invasive arthritis and nonfocal infections, suggesting that a generalised seasonal increase in host susceptibility may play a role in the pathogenesis of these common, severe infections.

\section{Acknowledgments}

This work was supported in part by grants from the Icelandic Center for Research, Rannís [grant number 100436021]; and the Landspitali University Hospital Science Fund (http:// rannis.is/english/home/). The funders had no role in study design, data collection and analysis, decision to publish, or preparation of the manuscript. This study was presented in part at ID week, San Diego, 17-21 October 2012.

\section{Conflict of interest}

None declared.

\section{Authors' contributions}

Lovísa Björk Ólafsdóttir: reviewed clinical data, analysed the data and wrote the paper. Helga Erlendsdóttir: generated the microbiology registry and wrote the paper. Jose MeloCristino: performed emm typing of the isolates. Daniel $\mathrm{M}$. Weinberger: performed statistical analysis and modelling and wrote the paper. Mario Ramirez: performed emm typing of the isolates and wrote the paper. Karl G. Kristinsson: generated the microbiology registry and wrote the paper. Magnús Gottfredsson: reviewed clinical and microbiology data, analysed the data and wrote the paper.

\section{References}

1. Efstratiou A. Group A streptococci in the 1990s. J Antimicrob Chemother. 2000;45 Suppl:3-12. http://dx.doi.org/10.1093/jac/45.suppl_1.3

2. O’Brien KL, Beall B, Barrett NL, Cieslak PR, Reingold A, Farley $M M$, et al. Epidemiology of invasive group a streptococcus disease in the United States, 1995-1999. Clin Infect Dis. 2002;35(3):268-76.

http://dx.doi.org/10.1086/341409

3. Stevens DL. Invasive group A streptococcus infections. Clin Infect Dis. 1992;14(1):2-11

http://dx.doi.org/10.1093/clinids/14.1.2

4. Centers of Disease Control and Prevention (CDC). CDC Streptococcus Laboratory. Atlanta: CDC. [Accessed: May 2012]. Available from: http://www.cdc.gov/ncidod/biotech/strep/ strepindex.htm

5. Facklam R, Beall B, Efstratiou A, Fischetti V, Johnson D, Kaplan $E$, et al. emm typing and validation of provisional $M$ types for group A streptococci. Emerg Infect Dis. 1999;5(2):247-53. http://dx.doi.org/10.3201/eido502.990209

6. Luca-Harari B, Ekelund K, van der Linden M, Staum-Kaltoft M, Hammerum AM, Jasir A. Clinical and epidemiological aspects of invasive Streptococcus pyogenes infections in Denmark during 2003 and 2004. I Clin Microbiol. 2008;46(1):79-86. http://dx.doi.org/10.1128/JCM.01626-07

7. Meisal R, Andreasson IK, Hoiby EA, Aaberge IS, Michaelsen TE, Caugant DA. Streptococcus pyogenes isolates causing severe infections in Norway in 2006 to 2007: emm types, multilocus sequence types, and superantigen profiles. J Clin Microbiol. 2010;48(3):842-51.

http://dx.doi.org/10.1128/JCM.01312-09

8. Sumby P, Porcella SF, Madrigal AG, Barbian KD, Virtaneva K Ricklefs SM, et al. Evolutionary origin and emergence of a highly successful clone of serotype $M_{1}$ group a Streptococcus involved multiple horizontal gene transfer events. J Infect Dis. 2005;192(5):771-82 http://dx.doi.org/10.1086/432514

9. Defining the group A streptococcal toxic shock syndrome. Rationale and consensus definition. The Working Group on Severe Streptococcal Infections. JAMA. 1993;269(3):390- http://dx.doi.org/10.1001/jama.269.3.390 http://dx.doi.org/10.1001/jama.1993.03500030088038

10. Aebi C, Ahmed A, Ramilo O. Bacterial complications of primary varicella in children. Clin Infect Dis. 1996;23(4):698-705. http://dx.doi.org/10.1093/clinids/23.4.698

11. Darenberg J, Luca-Harari B, Jasir A, Sandgren A, Pettersson $\mathrm{H}$, Schalen $\mathrm{C}$, et al. Molecular and clinical characteristics of invasive group A streptococcal infection in Sweden. Clin Infect Dis. $2007 ; 45(4): 450-8$. http://dx.doi.org/10.1086/519936

12. Gunnlaugsson S, Kristinsson KG, Steingrimsson O. Results of cultures and serotyping of S. pyogenes 1986-1993. Laeknabladid. 1995;81(10):728-32.

13. Lamagni TL, Darenberg J, Luca-Harari B, Siljander T, Efstratiou $A$, Henriques-Normark B, et al. Epidemiology of severe Streptococcus pyogenes disease in Europe. J Clin Microbiol. 2008 Jul;46(7):2359-67.

http://dx.doi.org/10.1128/JCM.00422-08

14. Luca-Harari B, Darenberg J, Neal S, Siljander T, Strakova L, Tanna A, et al. Clinical and microbiological characteristics of severe Streptococcus pyogenes disease in Europe. J Clin Microbiol. 2009;47(4):1155-65. http://dx.doi.org/10.1128/JCM.02155-08

15. Asmundsdottir LR, Erlendsdottir H, Gottfredsson M. Nationwide study of candidemia, antifungal use, and antifungal drug resistance in Iceland, 2000 to 2011. J Clin Microbiol. 2013;51(3):841-8. http://dx.doi.org/10.1128/JCM.02566-12

16. Asmundsdottir LR, Erlendsdottir H, Gottfredsson M. Increasing incidence of candidemia: results from a 20-year nationwide study in Iceland. J Clin Microbiol. 2002;40(9):3489-92. http://dx.doi.org/10.1128/JCM.40.9.3489-3492.2002

17. Centers for Disease Control and Prevention (CDC). Protocol for emm typing. Streptococcus pyogenes emm sequence database. Atlanta: CDC. [Accessed: April 2011]. Available from: http://www.cdc.gov/ncidod/biotech/strep/protocol_emm-type. htm

18. Population by sex and age 1841-2014. Reykjavik: Statistics Iceland; 2012. [Accessed: Jan 2013]. Available from: http:// statice.is/?PageID=1170\&src=https://rannsokn.hagstofa.is/ pxen/Dialog/varval.asp?ma=MANo0101\%26ti=Population+ by+sex+and+age+1841\%2D2014+++\%26path=../Database/ mannfjoldi/Yfirlit/\%26lang=1\%26units=Number

19. Weinberger DM, Krause TG, Molbak K, Cliff A, Briem H, Viboud $C$, et al. Influenza epidemics in Iceland over 9 decades: changes in timing and synchrony with the United States and Europe. Am J Epidemiol. 2012;176(7):649-55. http://dx.doi.org/10.1093/aje/kws140

20. Serfling RE. Methods for current statistical analysis of excess pneumonia-influenza deaths. Public Health Rep. 1963;78(6):494-506. "http://dx.doi.org/10.2307/4591848

21. Carapetis JR, Steer AC, Mulholland EK, Weber M. The global burden of group A streptococcal diseases. Lancet Infect Dis. 2005;5(11):685-94. http://dx.doi.org/10.1016/S1473-3099(05)70267-X

22. World Health Organization (WHO). Measles. Geneva: WHO. [Accessed April 2011]. Available from: http://www.who.int/ mediacentre/factsheets/fs286/en/

23. Vallalta Morales $M$, Soriano Navarro CJ, Salavert Lleti M, Montero Alonso M, Perez Belles C, Lopez Aldeguer J, et al. Group A streptococcal bacteremia: outcome and prognostic factors. Rev Esp Quimioter. 2006;19(4):367-75.

24. Lamagni TL, Neal S, Keshishian C, Powell D, Potz N, Pebody R, et al. Predictors of death after severe Streptococcus pyogenes infection. Emerg Infect Dis. 2009;15(8):1304-7. http://dx.doi.org/10.3201/eid1508.090264

25. Cleary PP, Kaplan EL, Handley JP, Wlazlo A, Kim MH, Hauser $A R$, et al. Clonal basis for resurgence of serious Streptococcus pyogenes disease in the 1980s. Lancet. 1992;339(8792):518-21. http://dx.doi.org/10.1016/0140-6736(92)90339-5

26. Aziz RK, Kansal R, Abdeltawab NF, Rowe SL, Su Y, Carrigan $D$, et al. Susceptibility to severe Streptococcal sepsis: use of a large set of isogenic mouse lines to study genetic and environmental factors. Genes Immun. 2007;8(5):404-15. http://dx.doi.org/10.1038/sj.gene.6364402

27. Nooh MM, Nookala S, Kansal R, Kotb M. Individual genetic variations directly effect polarization of cytokine responses to superantigens associated with streptococcal sepsis: implications for customized patient care. J Immunol. 2011;186(5):3156-63. http://dx.doi.org/10.4049/jimmunol.1002057

28. Cady A, Plainvert C, Donnio PY, Loury P, Huguenet D, Briand A, et al. Clonal spread of Streptococcus pyogenes emm 44 among homeless persons, Rennes, France. Emerg Infect Dis. 
2011;17(2):315-7.

http://dx.doi.org/10.3201/eid1702.101022

29. Tyrrell GJ, Lovgren M, St Jean T, Hoang L, Patrick DM, Horsman G, et al. Epidemic of group A Streptococcus M/emm59 causing invasive disease in Canada. Clin Infect Dis. 2010;51(11):1290-7. http://dx.doi.org/10.1086/657068

30. Lintges $M$, van der Linden $M$, Hilgers RD, Arlt S, Al-Lahham A, Reinert RR, et al. Superantigen genes are more important than the emm type for the invasiveness of group A Streptococcus infection. J Infect Dis. 2010;202(1):20-8. http://dx.doi.org/10.1086/653082

31. Dowell SF. Seasonal variation in host susceptibility and cycles of certain infectious diseases. Emerg Infect Dis. 2001;7(3):36974 .

http://dx.doi.org/10.3201/eido703.010301 http://dx.doi.org/10.3201/eido703.017301

32. Jean C, Louie JK, Glaser CA, Harriman K, Hacker JK, Aranki F, et al. Invasive group A streptococcal infection concurrent with $2009 \mathrm{H}_{1} \mathrm{~N}_{1}$ influenza. Clin Infect Dis.2010;50(10):e59-62. http://dx.doi.org/10.1086/652291

33. Tasher D, Stein M, Simoes EA, Shohat T, Bromberg M, Somekh E. Invasive bacterial infections in relation to influenza outbreaks, 2006-2010. Clin Infect Dis. 2011;53(12):1199-207. http://dx.doi.org/10.1093/cid/cir726

34. Lang PO, Samaras N, Samaras D, Aspinall R. How important is vitamin $D$ in preventing infections? Osteoporos Int. 2013;24(5):1537-53.

http://dx.doi.org/10.1007/s00198-012-2204-6

35. Steingrimsdottir L, Gunnarsson O, Indridason OS, Franzson L, Sigurdsson G. Relationship between serum parathyroid hormone levels, vitamin D sufficiency, and calcium intake. JAMA. 2005;294(18):2336-41.

http://dx.doi.org/10.1001/jama.294.18.2336 